\title{
Introducing Global Health Law
}

\section{Global Health Law}

\author{
Lawrence O. Gostin and \\ Benjamin Mason Meier
}

Global health law describes the legal frameworks that structure global health. Laws and regulations, when based on the best available evidence, can promote healthy behaviors, regulate hazardous activities, and ensure socially responsible corporate marketing and products. These regulatory frameworks operate in virtually every realm of health, including infectious and noncommunicable diseases, mental health, injuries, and the safety and effectiveness of vaccines, pharmaceuticals, and medical products. Law can help structure universally affordable, accessible, and equitable health systems that promote universal health coverage. Beyond discrete attention to health risks, the rule of law and good governance are crucial for ensuring health and well-being.

Where global health has come to frame efforts to advance public health across countries, law has become crucial to addressing the global health threats that have arisen in a rapidly globalizing world. Globalization has unleashed the spread of disease, connected societies in shared vulnerability, and highlighted the limitations of domestic law in ensuring global determinants of health. In this interconnected world, no country acting alone can stem health hazards that go beyond national borders. Yet if globalization has presented challenges to disease prevention and health promotion, global health law offers the promise of bridging national boundaries to advance global norms and alleviate health inequities.

Arising out of international health law - which has long structured multilateral cooperation to respond to infectious disease threats - global health law seeks to structure the contemporary governance architecture for global health. In responding to health harms throughout the world, global health law has "evolve[d] beyond its traditional confines of formal sources and subjects of international law" to advance global health with justice. ${ }^{1}$ This focus on global health has necessitated action beyond the reach of national governments, requiring both state and non-state actors to come together to respond to globalized health threats. Global health law seeks to frame this new governance to respond to the major health challenges of the twenty-first century.

The field of global health law has thus become a basis to conceptualize the legal institutions that apply to the changing public health threats, nonstate actors, and regulatory norms that structure global health. Beyond the traditional purview of international health law, global health law describes evolving legal efforts to address:

- New health threats - including non-communicable disease, injuries, mental health, dangerous products, and other globalized health threats,

- New health actors - including transnational corporations, private philanthropists, civil society, and other non-state actors, and

- New health norms - including "soft law" instruments, global strat-

Center on National and Global

Health Law. Professor Meier is an Associate Professor of Global Health Policy at the University of North Carolina at Chapel Hill and a Scholar at the O'Neill Institute for National and Global Health Law. This column will feature timely analyses and perspectives on law, policy, and justice in global health.

Lawrence O. Gostin, J.D., LL.D. (Hon.), is University Professor at Georgetown University and the Founding Linda D. Eं Timothy J. O'Neill Professor of Global Health Law at Georgetown University Law Center and Director of the World Health Organization Center on National and Global Health Law. Benjamin Mason Meier, J.D., LL.M., Ph.D., is an Associate Professor of Global Health Policy at the University of North Carolina at Chapel Hill and a Scholar at the O'Neill Institute for National and Global Health Law. 
egies and action plans, and other normative standards of global health policy. ${ }^{2}$

Global health law instruments can codify public health obligations across the global health landscape, realizing health and justice - bothwithin and among nations. These legal frameworks can promote good governance among national and global institutions, embracing values of transparency, setting targets, monitoring progress, structuring multisectoral engagement, and facilitating accountability. As legal scholarship in global health has expanded, it is necessary to consider global health law as a distinct part of health law.

This introductory column examines the development of the field, detailing the evolving scope and content of global health law. Beginning in the early history of international health law, national governments have long sought to address infectious disease threats through international regulations. This focus on international health law structured global governance for health in the aftermath of World War II, with the establishment of the World Health Organization (WHO) bringing states together to respond to common public health threats. Yet, WHO's early efforts to stem the international spread of infectious diseases have proven too narrow to meet the expanding legal challenges faced by a globalizing world. This column ends by framing the new field of global health law and outlining the leading global health threats that will be explored in future columns, demonstrating the power of this emerging field in conceptualizing the legal response to global health.

\section{Origins in International Health Law}

Global health law is built upon the foundations of international health law. International regulation of public health far predates modern health law, with international agreements long viewed by states as vital for collective action to safeguard national economic and security interests. ${ }^{3}$
Borne of a time when medicine was unable to treat illness, the rapid transmission of disease along trade routes forced the major trading powers to acknowledge that infectious diseases could no longer be construed as solely within the sovereign authority of independent states. ${ }^{4}$

This early "sanitary period," marked by its emphasis on the prevention of epidemic disease, determined the course of international public tered the widespread national ratification required for adoption. ${ }^{6}$

This legislative inertia would not be broken until widespread scientific agreement was reached on disease etiologies and government authorities. By the time of the 1892 Venice Conference, states had reached the necessary consensus on public health practice to draft and ratify a convention to prevent the spread of infectious disease. At the eleventh

\section{Arising out of international health law - which has long structured multilateral cooperation to respond to infectious disease threats - global health law seeks to structure the contemporary governance architecture for global health. In responding to health harms throughout the world, global health law has "evolve[d] beyond its traditional confines of formal sources and subjects of international law" to advance global health with justice. This focus on global health has necessitated action beyond the reach of national governments, requiring both state and non-state actors to come together to respond to globalized health threats. Global health law seeks to frame this new governance to respond to the major health challenges of the twenty-first century.}

health regulation through bilateral, regional, and multilateral treaties. The first International Sanitary Conference, held in Paris in 1851, brought together physicians and diplomats to reach consensus among those states having trading interests in the Mediterranean basin. ${ }^{5}$ These states held a second conference in Paris in 1859, with subsequent conferences held in Constantinople (1866), Vienna (1874), Washington, DC (1881), Rome (1885), Venice (1892), Dresden (1893), Paris (1894), and again in Venice (1897). While international sanitary regulations were crafted at various points in the long march of International Sanitary Conferences, none of these early regulations mus-
International Sanitary Conference in Paris, delegates in 1903 drafted the first International Sanitary Regulations of widespread applicability. ${ }^{7}$

The International Sanitary Regulations set the stage for the International Health Regulations (IHR) that followed and laid the groundwork following World War II for the development of international health law through WHO.

\section{Foundations of Global \\ Governance for Health}

The 1946 WHO Constitution would be the first treaty to codify states' expansive post-war mandate for medical care and underlying determinants of health, with WHO's consti- 
tutional framework piercing the veil of national sovereignty to respond to public health threats throughout the world. Complemented by a wide range of other United Nations agencies, which would support an expansive array of health determinants under their respective institutional mandates, WHO would have constitutional authority to adopt conventions, regulations, and recommendations on any public health matter. ${ }^{8}$ With this international legal authority to set regulatory norms for public health, WHO assumed responsibility for the IHR, creating a harmonized surveillance and reporting system for infectious disease control and setting both binding state obligations and permissible limitations on individual rights and commercial interests for disease prevention. ${ }^{9}$ However, beyond the IHR (last revised in 2005 to address past IHR weaknesses and reflect modern health threats), WHO has rarely exercised its lawmaking powers, with states in the World Health Assembly employing WHO's legal authority to develop only two other treaties: the 1967 Nomenclature Regulations and the 2003 Framework Convention on Tobacco Control.

There are limits to international health law in creating universal legal standards to ameliorate global health inequities. Where once public health was a central focus of international negotiation, the international regulation of public health has waned in international relations, as states have avoided limitations on their sovereign authority. ${ }^{10}$ Because of the state-centric nature of international law, these international health agreements have been focused on infectious diseases (that threaten security interests), dependent on voluntary agreement (exclusively by sovereign states), and reliant on international consensus (which results in unenforceable norms). ${ }^{11}$ International health law is seen as inherently incapable of facilitating collective action to address contemporary global health priorities. ${ }^{12}$ Although international health law remains a necessary area of research and practice, framingmultilateral cooperation to respond to global
Figure I

International Sanitary Conference

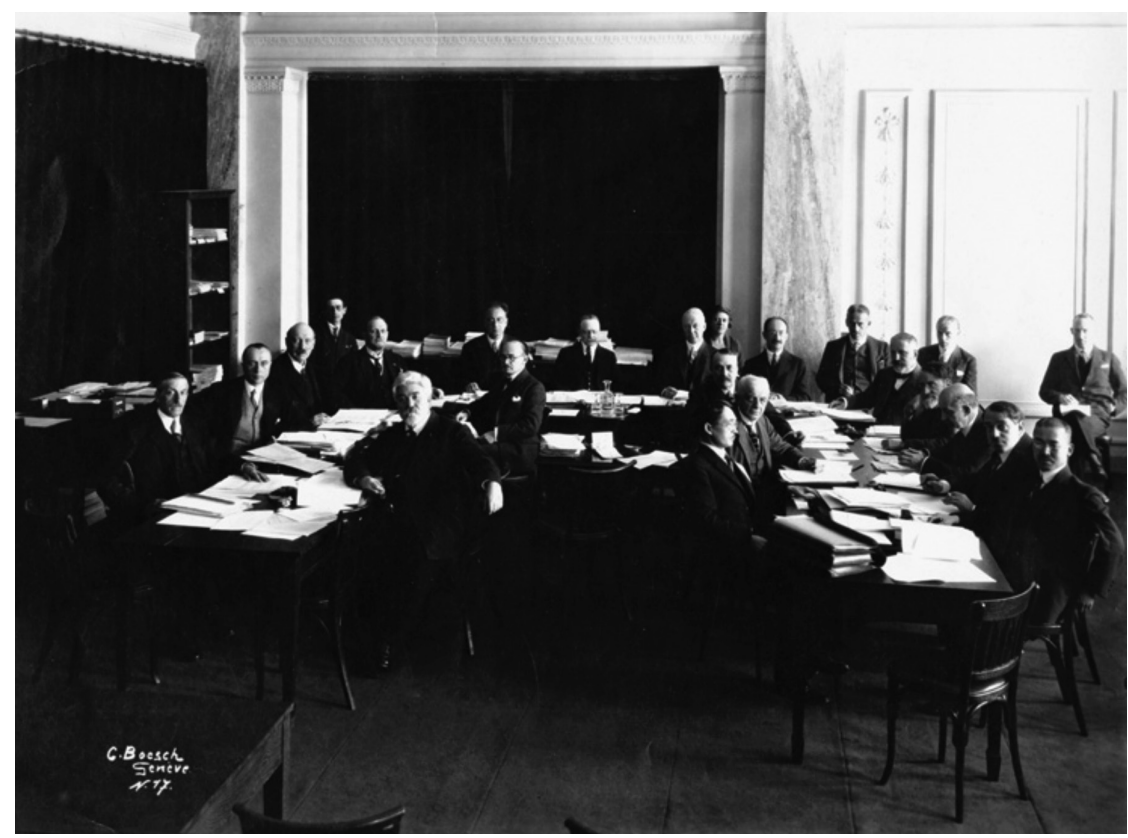

Figure 2

World Health Assembly

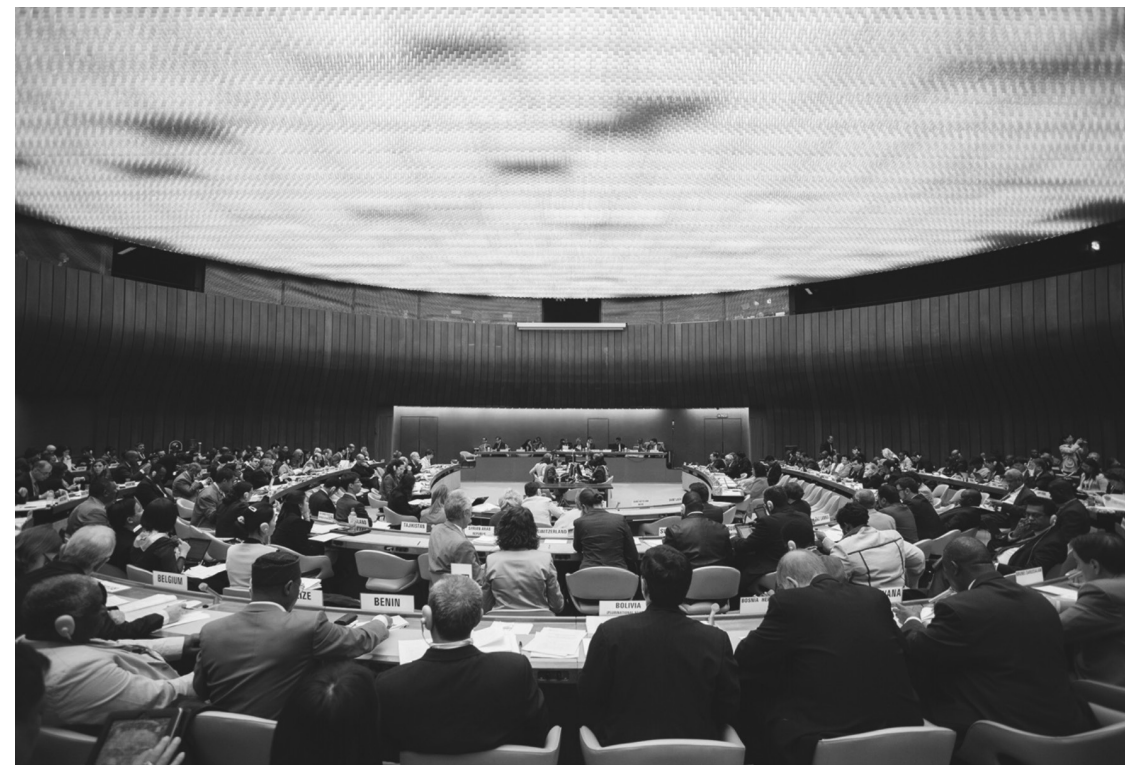

health security threats, such narrow legal frameworks are incommensurate with the rising health threats of a rapidly globalizing world. ${ }^{13}$

International health law cannot speak to contemporary changes in statehood, international relations, and global public goods for health. With public international law bear- ing most directly on states, which exercise only limited influence on the global forces that underlie public health, the underlying conditions for health are increasingly shaped by non-state actors, including global institutions, transnational corporations, individual philanthropists, and civil society. As international health 
WHO Director-General Tedros Adhanom Ghebreyesus

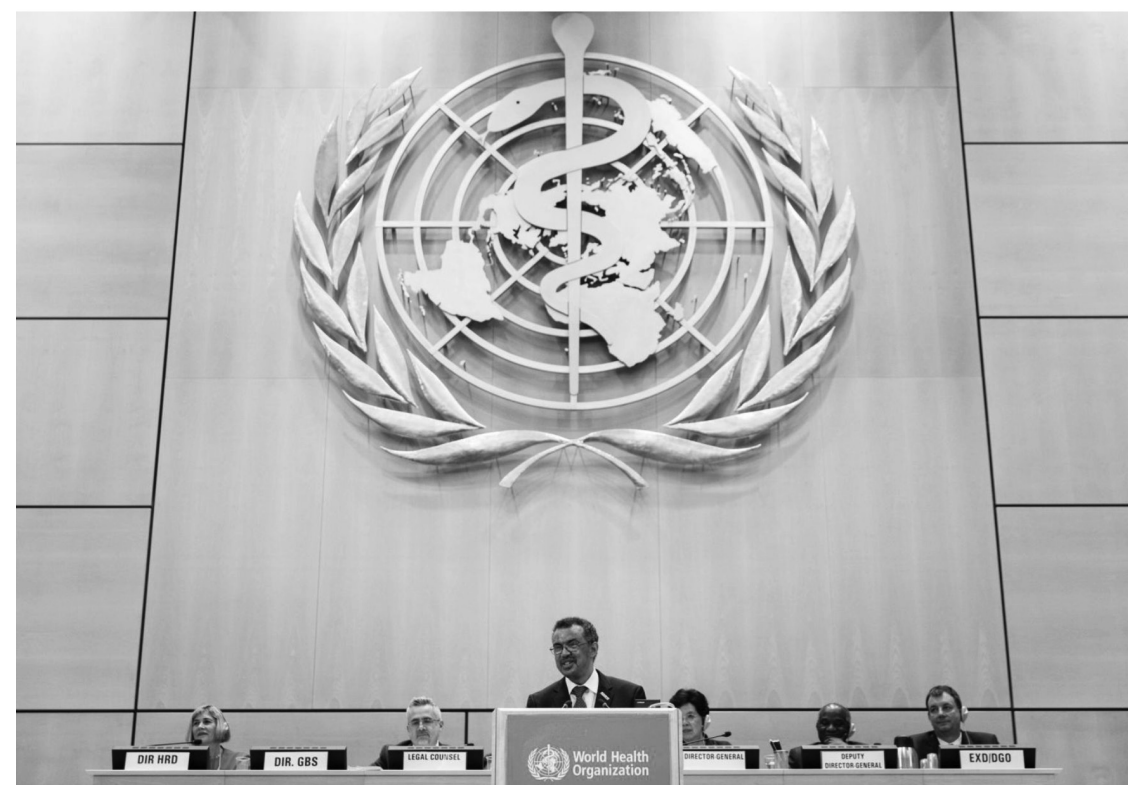

law has lost the capacity to influence public health across the world, "global health" has become the dominant terminology to describe the interdependent needs of all peoples, rather than those of particular countries, and the global action necessary to meet these needs across nations, actors, and sectors. ${ }^{14}$ This focus on global health, addressing global determinants of public health, demands an expanded scope and influence of health law to meet the public health needs of an interconnected world, redressing health inequities within and across countries through global health law. ${ }^{15}$

\section{Applications to a Globalizing World}

Law is crucial to the advancement of global health. Structuring health outcomes through law, legal instruments shape underlying determinants of global health, and these "legal determinants of health" provide a path to safeguard public health in a globalizing world. ${ }^{16}$ Yet legal capacities and government authorities differ greatly across countries, undercutting efforts to assure global equity in health. ${ }^{17}$ There is a rising need for evidencebased law reforms - in all countries and through global governance. ${ }^{18}$ Global health law presents a legal
In an expanding global health governance landscape, safeguarding the public's health requires cooperation among state and non-state actors, and this coordination can be fostered through global health law. International health law continues to govern the actions of national governments, especially where binding obligations on states are necessary to prevent infectious disease through state action; ${ }^{21}$ however, international relations between states does not encompass the entirety of contemporary global health diplomacy. ${ }^{22}$ Shifting from international health law (applicable to states) to global health law (applied to both state and non-state actors), a multi-level proliferation of international, national, nongovernmental, and corporate actors have organized to address a multi-sectoral array of determinants of health. ${ }^{23}$ Global health law can frame this expanding landscape for global health, coordinating the global community of state and nonstate actors through institutions of global governance. ${ }^{24}$

Global health law shapes the legal foundation of global governance for health. Global governance has become crucial in developing legal norms and implementing those norms through global institutions. ${ }^{25}$ Operating under global health law, well governed institutions can be more effective in setting standards, coordinating disparate actors, forming partnerships with key stakeholders, and developing consensus on shared goals for global health. ${ }^{26}$ These new instruments of global health law endow global institutions with the tools to negotiate a shared vision of good governance for global health, coordinate with other organizations across sectors, and align national law with global health law to advance public health throughout the world. ${ }^{27}$ Facilitating accountability for these global health goals, global health law can provide an institutional basis for developing benchmarks, monitoring progress, and enhancing compliance. $^{28}$

The application of global health law can thereby establish a normative framework for achieving global health with justice. In creating an 
imperative for global health institutions to meet an expanding set of global challenges to underlying determinants of health, global health law can codify normative frameworks to realize the human rights that underlie global health. ${ }^{29}$ As the limitations of international law have moved global health law beyond the confines of international legal agreements, stakeholders have engaged a diverse array of state and non-state actors through the rise of new policy institutions - institutions developed through their normative foundations in justice. ${ }^{30}$ Global health law can solidify these vital norms for justice across institutions, providing a foundation for human rights in global health. ${ }^{31}$

\section{Column on Global Health Law}

The expansion of health law scholarship to encompass global health law has laid out a legal framework to structure efforts by the global community to advance public health. Through hard and soft law norm-setting, global health law seeks to create new policy institutions to alter behaviors, sustain funding, and coordinate partnerships. ${ }^{32}$ Global health law extends beyond the scope of discrete health-focused international legal agreements between national governments - addressing an encompassing set of global health determinants through the obligations of state and non-state actors, structuring new forms of global governance reflective of the major global health threats, and framing the normative foundations necessary to realize global health with justice.

This column will seek to capture these contemporary advances in the theory, research, and practice of global health law. Early columns will focus on the role of law in:

- global health security and the International Health Regulations,

- non-communicable diseases and WHO framework conventions,

- universal health coverage under the Sustainable Development Goals,
- immunization law to achieve widespread vaccination and disease prevention,

- zoonotic disease and the need for laws at the intersection of public health, animal health, and environmental health,

- international trade law in structuring commercial determinants of health,

- planetary health and laws to mitigate and adapt to climate change, and

- human rights law as a foundation of global health governance.

This quarterly examination of contemporary advances in global health law will build the research foundation for global health law reforms, analyze evidence-based legal interventions that promote public health, and explore the normative influence of human rights in global health. Through these columns, it will be possible to develop an understanding of legal "best practices in global health," extending policy surveillance and legal epidemiology globally to understand how law reforms can best succeed in improving public health.

\section{Conclusion}

With the rise of the field of global health law, this column seeks to expand the reach of this interdisciplinary scholarship as part of the larger field of health law. Global health law has become central to health law in a globalizing world, and it is necessary to broaden the links between domestic and global health law in legal theory, empirical research, and normative application. Extending burgeoning global health analysis in the Journal of Law, Medicine E Ethics, this column will provide a home for scholars to apply legal analysis to promote global health, serving as a central resource for academics, practitioners, and advocates in the years to come.

\section{Note}

The authors are grateful to Lindsay Wiley, Montrece Ransom, Edward Hutchinson, and Aaron Kesselheim for recognizing the importance of global health law to the advancement of health law and for provid- ing thoughtful advice in developing this inaugural column. The authors have no conflicts to declare.

References

1. L.O. Gostin and A.L. Taylor, "Global Health Law: A Definition and Grand Challenges," Public Health Ethics 1, no. 1 (2008): 53-63, 55.

2. L.O. Gostin, Global Health Law (Cambridge: Harvard University Press, 2014).

3. O. Aginam, Global Health Governance: International Law and Public Health in a Divided World (Toronto: University of Toronto Press, 2005)

4. D.P. Fidler, International Law and Infectious Diseases (New York: Clarendon Press, 1999).

5. D.P. Fidler, "The Globalization of Public Health: The First 100 Years of International Health Diplomacy," Bulletin of the World Health Organization 79 , no. 9 (2001): 842-849.

6. N. Howard-Jones, The Scientific Background of the International Sanitary Conferences, 1851-1938 (Geneva: World Health Organization, 1975).

7. D. Porter, Health, Civilization and the State: A History of Public Health from Ancient to Modern Times (New York: Routledge, 1998).

8. Constitution of the World Health Organization (Geneva: World Health Organization, 1946).

9. Burci, Gian Luca and C.-H. Vignes, The World Health Organization (London: Kluwer Law International, 2004).

10. L.O. Gostin, "World Health Law: Toward a New Conception of Global Health Governance for the 21st Century," Yale Journal of Health Policy, Law ङ Ethics 5, no. 1 (2005): 413-424.

11. S.J. Hoffman, J.-A. Røttingen, and J. Frenk, "Assessing Proposals for New Global Health Treaties: An Analytic Framework," American Journal of Public Health 105, no. 8: 1523-1530.

12. L.O. Gostin, "Meeting Basic Survival Needs of the World's Least Healthy People: Toward a Framework Convention on Global Health," Georgetown Law Journal 96, no. 2 (2008): 331-392.

13. R. Magnusson, "Non-Communicable Diseases and Global Health Governance: Enhancing Global Processes to Improve Health Development," Globalization and Health 3, no. 2 (2007): 1-16.

14. T.M. Brown, M. Cueto, and E. Fee,"The World Health Organization and the Transition from 'International' to 'Global' Public Health," American Journal of Public Health 96, no. 1 (2006): 62-72.

15. S. Moon, "Global Health Law and Governance: Concepts, Tools, Actors and Power," in G.-L. Burci and B. Toebes (eds) Research Handbook on Global 
Health Law (Northampton: Edgar, 2006): 24-54.

16. L.O. Gostin, J.T. Monahan, J. Kaldor, M. DeBartolo, E. Friedman, et al., "The Legal Determinants of Health: Harnessing the Power of Law for Global Health and Sustainable Development," The Lancet 393, no. 10183 (2006): P1857-1910.

17. L.O. Gostin, "The Lancet Commission on Global Health Law: The Transformative Power of Law to Advance the Right to Health," Journal of Global Health Science 1, no. 1 (2019): e5.

18. S.J. Hoffman, M.J.P. Poirier, S.R.Van Katwyk, P. Baral, and L. Sritharan,"Impact of the WHO Framework Convention on Tobacco Control on Global Cigarette Consumption: Quasi-experimental evaluations using interrupted time series analysis and insample forecast event Modelling," British Medical Journal 365 (2019): 12287.

19. B. Toebes, "Global Health Law: Defining the Field," in G. L. Burci and B. Toebes (eds). Research Handbook on Global Health Law (Northampton: Edgar, 2018): 2-23.

20. L. Wiley, "Moving Global Health Law Upstream: A Critical Appraisal of Global Health Law as a Tool for Health Adaptation to Climate Change,"
Georgetown International Law Review 22, no. 3 (2010): 439-489.

21. S.E. Davies, A. Kamradt-Scott, and S. Rushton, Disease Diplomacy: International Norms and Global Health Security (Baltimore: Johns Hopkins University Press, 2015).

22. I. Kickbusch, G. Silberschmidt, and P. Buss, "Global Health Diplomacy: The Need for New Perspectives, Strategic Approaches and Skills in Global Health," Bulletin of the World Health Organization 85, no. 3 (2007): 230-232.

23. N. Szlezák, B.R. Bloom, D.T. Jamison, G.T. Keusch, C.M. Michaud, S. Moon, and W.C. Clark, "The Global Health System: Actors, Norms, and Expectations in Transition," PLoS Medicine 7, no. 1 (2010): e1000183.

24. L.O. Gostin and D. Sridhar "Global Health and the Law," Nere England Journal of Medicine 370 (2014): 1732-1740.

25. N.D. White, "Lawmaking" in J. K.Cogan, I. Hurd, and I. Johnstone (eds) The Oxford Handbook of International Organizations (Oxford: Oxford University Press, 2016).

26. J. Klabbers, Advanced Introduction to the Law of International Organizations (Cheltenham: Elgar, 2015).
27. B.M. Meier and L.O. Gostin, "Framing Human Rights in Glboal Health Governance," in B.M. Meier and L.O. Gostin (eds) Human Rights in Global Health: Rights-Based Governance for a Globalizing World (New York: Oxford University Press, 2018): 63-86.

28. Gostin 2014, supra note 2.

29. R. Magnusson, Advancing the Right to Health: The Vital Role of Law (Geneva: World Health Organization, 2017); L.O. Gostin and B.M. Meier, R. Thomas, V. Magar, and T. A. Ghebreyesus, "70 Years of Human Rights in Global Health: Drawing on a Contentious Past to Secure a Hopeful Future," The Lancet 392 (2018): 2731-2735.

30. J.P. Ruger, Global Health Justice and Governance (Oxford University Press, 2018).

31. B.M. Meier and L.O. Gostin, Human Rights in Global Health: Rights-Based Governance for a Globalizing World (New York: Oxford University Press, 2018).

32. Gostin 2014, supra note 2. 